\title{
Relationship between household income and child mortality in Nigeria
}

\author{
Richardson Kojo Edeme*, Innocent A. Ifelunini, Okereke Obinna S.
}

Department of Economics, University of Nigeria, Nsukka, Nigeria

Email address:

kojodynamics@yahoo.com (R. K. Edeme), innocent.ifelunini@unn.edu.ng (I. A. Ifelunini)

\section{To cite this article:}

Richardson Kojo Edeme, Innocent A. Ifelunini, Okereke Obinna S.. Relationship between Household Income and Child Mortality in Nigeria. American Journal of Life Sciences. Special Issue: Science, Society and Policy: Driving Towards Utopia or Dystopia. Vol. 2, No. 6-4, 2014, pp. 1-12. doi: 10.11648/j.ajls.s.2014020604.11

\begin{abstract}
To attain sustainable development goals, reduction in child mortality is necessary. However, a major challenge exists in the procurement of healthcare services by individuals which is determined to a large extent by their level of income. Adopting random effect and fixed effect methodology and using survey data from Multiple Indicator Cluster Survey (2012) and General Household Survey (2012), this study examines the relationship between household income and child mortality. For the analysis, infant mortality rate, under-five mortality rate and neonatal mortality rate was modeled against household income and controlled for access to anti-natal care, access to safe water and sanitation, neonatal mortality rate, maternal education and household size in Nigeria. Results obtained show that household income has significant effect on neonatal mortality rate in Nigeria but household income has insignificant effect on infant and under-five mortality rates in Nigeria. Results also show that household size has significant effect on infant mortality rate and neonatal mortality rate in Nigeria. The study equally found that access to anti-natal care has significant effect on under-five mortality rate in Nigeria.
\end{abstract}

Keywords: Household Income, Child Mortality, Multiple Indicator Cluster Survey, Generalized Household Survey, Random Effect, Random Effect

\section{Introduction}

In recent years, public health, especially child healthcare related programme has received renewed attention as part of effort towards the attainment of the health-related Millennium Development Goals. This is because approximately 10 million infants and children under five years of age die each year, with large variations in under-five mortality rates, across regions and countries [54]. According to UNICEF $(2009,2010)$, the decline in child mortality in Africa has been slower since 1980 than in the 1960s and 1970s. Of the thirty countries with the world's highest child mortality rates, twenty-seven are in sub-Saharan Africa. The region's under-five mortality in 1998 was 173 per 1000 live births compared to the minimum goal of 70/1000 internationally adopted in the 1990 World Summit.

Studies have revealed that the progress countries have made toward reaching their goals of reducing by two- third childhood mortality based on the 1990 progress has been mixed. For about two decades, the annual number of underfive deaths only fall from around 12.4 million to about 8.1 million in 2009 - nearly 22,000 per day or 15 every minute [55]. Though, when considering the trend from different reports since 1990 , it is clear that under-five mortality had fallen.

Nigeria with a high level of infant and child mortality rate has been classified as among the 30 countries with the highest early mortality rate in the world, given that majority of the death occur among infants and young children. Available data on under-five mortality depicts that it varies tremendously over the years. For instance, between 2007 and 2011, from 86 deaths per 1,000 live births to 105 deaths per 1,000 live births and infant mortality rate of 75 deaths per 1,000 live births. Beside, every year, about 5.9 million babies are born and nearly one million children die before the age of five years. One quarter of all infant deaths is newborns 241,000 babies each year. According to a report released [34], 75 children per 1,000 live births die before their first birthday (40 per 1,000 before the age of one month and 35 per 1,000 between one and twelve months). Overall, 157 children per 1,000 live births or about 1 child out of 6 , die before reaching age five [34].

In all high-mortality countries there are a few sub-groups 
that experience low early mortality risks comparable to the overall levels in more advanced societies. For Nigeria, estimates of neonatal, infant and overall early childhood mortality rates for the $2000-2009$ period point to striking regional inequalities in child survival. More definitive statements about these regional differentials would require rigorous statistical analysis of the data sets from which they were derived. It is likely that they mainly reflect differences in prevailing levels of household poverty, provision of public utilities and social services, and in the educational levels of the population of these regions.

The study carried out by [43, 44 and 54] have demonstrated that poor children have worse health outcomes than do non-poor children and infant mortality rates have been shown to be inversely related to socioeconomic status. Similarly, studies have shown that poverty alone does not entirely explain this relationship. When considered at the population level, the absolute level of poverty does not seem to explain fully the worse health outcomes of poor individuals (see for example [21]). Once individuals and families are able to meet their basic needs, their relative income seems to play an increasing role in determining the health outcomes of the community in which they live [52]. However, it is opined that once a society progresses beyond the point of absolute deprivation and people are able to meet their basic needs, then it is the distribution of income within the society that affects health outcomes. A study that provides an understanding between household income and child mortality, apart from being apt, it is also imperative for policy analysis toward the attainment of sustainable development goals.

Although the income inequality hypothesis has been explored extensively in literature with majority of the research focusing on adult health, the outcomes of such studies are mixed $[4,24,52,25,21,11]$. The pediatric health indicators for which the relationship has been investigated are neonatal mortality rates, child mortality rates, preterm birth rates, low birth rates, child overweight status, mental health problems, bullying, teen violence, teen pregnancy rates, and high school dropout rates. Also within-country studies such as [8, 10, 31, 48], inter-alia, have shown that low economic status is associated with increased rates of infant and child mortality. But providing the relationship between household income and child mortality in Nigeria remains unexplored. This study is therefore, undertaken to examine the relationship between household income and child mortality in Nigeria.

\section{Theoretical and Empirical Literature}

\subsection{The Relative Deprivation and Gratification Theory}

The relative deprivation theory is a social comparison theory enunciated by [27]. The theory postulates that people mainly compare themselves to others who are more advantaged in life than they are, and pay less attention to those who are less advantaged. An important disparity is between individual relative deprivation in which an individual compares his or her personal situation to the situation of other individuals, and group relative deprivation in which a person compares his or her relevant group's situation with the situation of another group. Growing inequality can affect both sorts of relative deprivation, but we mainly emphasize individual comparisons not group comparisons. Individuals who are more advantaged make individuals who are less advantaged feel relatively deprived. As inequality increases, the opportunity for negative social comparisons increases because the distance between the rich and poor increases if individuals mostly compare themselves to the poorest people in society rather than to the richest. Thus, increase in inequality would make most people feel better, because the distance between themselves and the bottom would grow. Implied here is that if people mostly compare themselves to some real or imagined national average, increase in inequality will make the rich feel richer and the poor feel poorer. However, the effect on the mean level of subjective well-being would depend on the functional form of the relationship between income differences and subjective well-being, which is unknown. But [26] and [52] contend that inequality worsens adult health when social comparison is adopted in this regard.

\subsection{The Individual Income Interpretation Theory}

References [25] and [15] opine that curvilinear relation between income and health at the individual level is a sufficient condition to produce health differences between populations with the same average income but different distributions of income. This theory assumes that determinants of population health are completely specified as attributes of independent individuals and that health effects at the population level are merely attributes of individual effect. In contrast, however, [23] and [9] suggest that there may also be important contextual determinants of health and understanding these potential multilevel effects that use measures of income distribution and individual income to examine health differences across individuals and aggregated units is imperative.

Empirically, analysis of health differences among individuals and contextual health effects of income distribution have remained after adjustment for individual income in most studies. Not surprisingly, these studies found that individual income was more strongly related to individual differences in health than to income distribution. A study by [53] employed a simulation technique to explore the contribution of individual income to aggregate health differences in United States of America. They were able to show that the individual mechanism explained only a modest proportion of the observed aggregate variation in mortality at the level. In furtherance, several other studies such as [16], [7], [56] and [28] investigated the determinant of child mortality for effective healthcare intervention and programme evaluation of clinical and financial outcomes. Others such as [32], [1], [39] and [36] focus on the determinant of child mortality. 
A different strand in literature associated with child healthcare is child mortality risks. This dimension can be viewed from the framework of a health production function to depend on both observed health inputs and unobserved biological endowment or frailty and excluding these unobserved attributes or existing relation between children within a family may lead to inefficient estimators [40]. In assessing the effect of different determinants of healthcare on child health, different framework has been adopted. For instance, [31], [42] and [32] distinguish between socioeconomic (exogenous) and biomedical (endogenous) variables. The effects of these exogenous variables are found to be indirect as they operate within the endogenous biomedical variables called proximate determinants. It was however, the work of [34] that further categorize these proximate determinants into maternal, environmental, nutrient deficiency, injuries and personal illness. In a comparative study of rural areas of Ghana, Egypt, Thailand and Brazil, [6] found that children's health is affected by environmental conditions and the economic status of the household. Reference [17] utilizes duration modeling to assess the impacts of water and sanitation on child mortality in Egypt, although the impact of sanitation was found to be more pronounced than water. The result also shows that access to municipal water reduces the risk of mortality. In another study, [30] adopted a Bayesian geo-additive survival model to analyze the extent of child mortality in Nigeria and the result shows the existence of a district-specific geographical variation in the level of child mortality. In a similar study on the environmental determinants of child mortality in rural China, [22] developed a flexible parametric hazard rate framework in analyzing child mortality. The model predicts significant correlation between child mortality and access to electricity, provision of sanitation facilities, improving maternal education and reducing indoor air pollution. Their findings among others show that the use of clean cooking fuels, access to safe water and sanitation reduces the risks of child mortality. For Ethiopia study, [50] constructed three hazard models: the Weibull, the piecewise Weibull and the Cox model to examine three age-specific mortality rates by location, female education attainment, religion affiliation, income quintile, and access to basic environmental services (water, sanitation and electricity). The results show a strong significant relationship between child mortality and poor environmental conditions. The authors of [44] adopted indirect method to estimate levels and trends of mortality in Malawi. The results indicate that source of drinking water and sanitation facilities are strong predictors of child mortality.

In estimating the level of mortality, studies in Nigeria have employed different approaches. For instance, [25] combine Samoza method, univariate, and bivariate analyses to calculate mortality indices for each woman in Ondo and Ekiti state while [38] applied multiple regressions with autocorrelation adjustment to estimate mortality in Enugu state. Also [3] employ the multilevel logistic regression while [20] use multivariate logistic regression in their study. A major conclusion from these studies is that demographic, socio-economic and environmental factors such as source of drinking water and sanitation facilities are significantly related to infant and child mortality. Collaborating this, [14], in a study of South-western Nigeria found that child mortality rate is greatly dependent on environmental variables such as source of drinking water and a child care behaviour factor. Using proximate determinant framework, [2] investigated developmental implications of early mortality factors in Nigeria and found that a combination of higher parental income and higher density of modem health facilities constitute major factors that are most likely to bring about sustained reductions in early mortality levels. The study also provided evidence that various regions and states in Nigeria do not, on the whole, show up maternal education as a primary early mortality reducing factor as acclaimed in other emerging economies.

\section{Methodology}

\subsection{Methodological Framework}

The methodological framework underlying this study is the Child Survival Framework developed by [31]. This approach allows for careful tracing of the pathways through which socioeconomic factors impinge on child health and survival in the developing world. The framework presumes that under optimal conditions, less than five percent of newborn infants will die during their first 60 months of life. Beside, a higher death probability in any society is due to the effects of social, economic, environmental and biological forces, which necessarily operate the outcome of disease processes while specific diseases and nutrient deficiencies are biological outcomes of the operation of the proximate determinants. Also, a child's death is the cumulative consequence of multiple disease processes including their biosocial interactions.

The child survival framework identifies five groups of mechanisms through which socioeconomic variables can influence the risk of mortality. They are - maternal factors (age, parity, and birth spacing); environmental contamination (air, food/water/fingers, skin and insect vectors); nutrient deficiency; personal illness control; and injury. It recognizes the possibility of interactions among these factors, which are assumed to influence a child's transition from a healthy to a sick state and vice versa. More so, the framework states that maternal education can be thought of as influencing child health and survival through better health care practices, hygiene, preventive care and treatment, the allocation of more resources to child care, use of appropriate weaning foods, timely visits to prenatal clinics, optimal birth spacing, and maintenance of home hygiene. Women from low income households relative to those from high income ones, may be exposed to greater risk of child death due to their own poor nutritional status and rapid childbearing, raising children in less sanitary environments and possessing more limited capacity to provide adequate nutrition to their children or to 
exploit available medical services in the event of a child's illness.

The usefulness of the Mosley-Chen framework here is that it enables a categorisation of the various possible determinants of child health and survival in a way that allows the integrative linking of environmental conditions, dietary status, health care, reproductive patterns and disease states, that is, the proximate determinants, on one hand, and the socioeconomic, that is, the ultimate factors, on the other.

\subsection{Model Specification}

Following the leads of [18] and [4] with modifications, the matrix notation of a mixed effect model can be specified as:

$$
y=X \beta+Z u+\epsilon
$$

Where $y$ is a vector of observations, with mean
$E(y)=X \beta, \beta$ is a vector of fixed effects $\boldsymbol{u}$ is a vector of random effects with mean $E(u)=0$ and variance-covariance matrix $\operatorname{var}(u)=G$, is a vector of IID random error terms with mean $E(c)=0$ and variance $\operatorname{var}(\epsilon)=R, X$ and $Z$ are matrices of regressors relating the observations $y$ to $\beta$ and $u$.

Arising from the above and in line with our variables, the functional relationship between dependent and explanatory variables can be specified respectively as:

$$
\begin{aligned}
& \mathrm{IMR}=\mathrm{f}(\text { Hhc }, \text { Anc, Sws, Med, Hhs }) \\
& \mathrm{UMR}=\mathrm{f}(\text { Hhc }, \text { Anc, Sws, Med, Hhs }) \\
& \mathrm{NMR}=\mathrm{f}(\text { Hhc, Anc, Sws, Med, Hhs })
\end{aligned}
$$

In its linear form, the mixed effects form of models 2, 3 and 4, can be expressed as:

$$
\begin{aligned}
& \mathrm{IMR}_{\mathrm{i}}=\left(\beta_{0}+\mu_{\mathrm{i} 1}\right)+\beta_{1} \mathrm{Hhc}_{\mathrm{i}}+\beta_{2} \mathrm{Anc}_{\mathrm{i}}+\beta_{3} \mathrm{Sws}_{\mathrm{i}}+\beta_{4} \mathrm{Med}_{\mathrm{i}}+\beta_{5} \mathrm{Hhs}_{\mathrm{i}}+\varepsilon_{\mathrm{i} 1} \\
& \mathrm{UMR}_{\mathrm{i}}=\left(\alpha_{0}+\mu_{\mathrm{i} 2}\right)+\alpha_{1} \mathrm{Hhc}_{\mathrm{i}}+\alpha_{2} \mathrm{Anc}_{\mathrm{i}}+\alpha_{3} \mathrm{Sws}_{\mathrm{i}}+\alpha_{4} \mathrm{Med}_{\mathrm{i}}+\alpha_{5} \mathrm{Hhs}_{\mathrm{i}}+\varepsilon_{\mathrm{i} 2} \\
& \mathrm{NMR}_{\mathrm{i}}=\left(\lambda_{0}+\mu_{\mathrm{i} 3}\right)+\lambda_{1} \mathrm{Hhc}_{\mathrm{i}}+\lambda_{2} \mathrm{Anc}_{\mathrm{i}}+\lambda_{3} \mathrm{Sws}_{\mathrm{i}}+\lambda_{4} \mathrm{Med}_{\mathrm{i}}+\lambda_{5} \mathrm{Hhs}_{\mathrm{i}}+\varepsilon_{\mathrm{i} 3}
\end{aligned}
$$

where IMR $=$ Infant mortality rate; Anc $=$ Access to antinatal care; UMR = Under-five mortality rate; Sws = Access to safe water and sanitation; NMR = Neonatal mortality rate; Med = Maternal education; Hhc $=$ Household income; Hhs $=$ Household size; the $\varepsilon_{\mathrm{ij}} \sim \mathrm{N}\left(0, \delta^{2}\right), \mu_{\mathrm{ij} \tilde{j}} \mathrm{~N}\left(0, \delta_{\mathrm{u}}^{2}\right)$ i.i.d; $\mu_{\mathrm{ij}}, \varepsilon_{\mathrm{ij}}$ are independent variables; $\beta_{i}, \alpha_{i}$, and $\lambda_{i}$ are fixed effect while, $\mu_{\mathrm{ij}}$ are random effect

As in the Bayesian approach, a decision is to be taken as to the prior distribution, but that distribution may contain unknown parameters that are estimated from the data. To overcome the problem, we employ the Penalized likelihood procedure. We show that the penalized likelihood may be derived from a mixed model as an approximation to the marginal likelihood after applying the Laplace approximation. Moreover, the penalty coefficient, often derived from a heuristic procedure, is estimated by maximum likelihood as an ordinary parameter. The data for the study were sourced from Multiple Indicator Cluster Survey and General Household Survey data from National Bureau of Statistics. STATA (11) econometric package was employed for estimation.

\section{Empirical Results}

Before the random effect and fixed effects analysis, we

\begin{tabular}{|c|c|c|c|c|c|c|}
\hline \multirow{2}{*}{ Variable } & \multicolumn{3}{|c|}{ Urban } & \multicolumn{3}{|c|}{ Rural } \\
\hline & Obs & Mean & Std. Dev. & Obs & Mean & Std. Dev. \\
\hline Hhsize & 9409 & 4.066 & 2.459 & 25491 & 4.570 & 2.511 \\
\hline Hhagey & 9409 & 47.798 & 16.263 & 25491 & 47.594 & 15.896 \\
\hline Spouses & 9409 & 0.733 & 0.628 & 25491 & 0.922 & 0.676 \\
\hline Nfdelec & 9409 & 5557.319 & 12802.180 & 25491 & 1263.568 & 60622.762 \\
\hline Nfdchar & 9409 & 457.960 & 6696.016 & 25491 & 85.516 & 1134.794 \\
\hline Nfdkero & 9409 & 7526.311 & 16112.280 & 25491 & 4508.229 & 13940.530 \\
\hline Nfdcloth & 9409 & 11670.880 & 45439.970 & 25491 & 7663.572 & 30765.680 \\
\hline Fdtotpr & 9409 & 22246.220 & 68828.580 & 25491 & 83383.010 & 128833.200 \\
\hline Edtexp & 9409 & 9821.238 & 39887.370 & 25491 & 3818.944 & 25512.130 \\
\hline Hlhospt & 9409 & 3405.800 & 33163.380 & 25491 & 4329.450 & 34227.240 \\
\hline Hleqpt & 9409 & 433.326 & 2863.902 & 25491 & 207.852 & 2072.008 \\
\hline Hhtexp & 9409 & 376996.900 & 602500.600 & 25491 & 316547.800 & 529218.800 \\
\hline Nfdutil & 9409 & 327.374 & 1742.143 & 25491 & 28.680 & 559.171 \\
\hline
\end{tabular}
present the descriptive statistics of the variables of the household characteristics. The essence of this is to enable us determine if there is any significant difference in income and expenditure pattern in the urban and rural area. The outcome is presented in Table 1 below.

Table 1. Descriptive statistics of household characteristics 


\begin{tabular}{lcccccc}
\hline \multirow{2}{*}{ Variable } & \multicolumn{2}{c}{ Urban } & \multicolumn{2}{c}{ Rural } \\
\cline { 2 - 7 } & Obs & Mean & Std. Dev. & Obs & Mean & Std. Dev. \\
\hline Nfdfmtn & 9409 & 8753.054 & 35078.720 & 25491 & 7343.500 & 27251.790 \\
Nfdpetro & 9409 & 4087.413 & 24959.470 & 25491 & 1270.494 & 11480.690 \\
Nfdptax & 9409 & 28.991 & 1187.927 & 25491 & 12.519 & 868.454 \\
Nfdrntac & 9409 & 13929.600 & 57896.830 & 25491 & 1663.977 & 20777.610 \\
\hline
\end{tabular}

Note: Hhsize = household size; Hhagey = household head; Nfdelec = household having access to electricity; Nfdfwood = household using firewood; Nfdchar $=$ household that uses charcool; Nfdkero $=$ household that uses kerosene; Nfdcloth $=$ housing expenditure on clothing and footwear; Edtotpr $=$ household health expenditure; Edtexp = household education expenditure; Hlhospt $=$ Access to hospital; Hlinsur $=$ access to health insurance; Hleqpt $=$ healthcare equipment; Nfdutil = healthcare utilities; Nfdmtn = routine household maintenance; Nfdpetrol = access to petrol for private use; Nfdptax $=$ household payment for property service charge; Nfdrntac = payment for house rent

Table 1 shows that average size of households in the urban area is about four people per household while it is about five persons per household in the rural area. No significant difference was observed between the years of household heads in the urban and rural areas. With an average value of 48 , the age of household head in the urban and rural area is the same. In terms of amenities, about 5,557 out of 9,409 households surveyed in the urban area use electricity which represents $59 \%$, while about 1,264 out of 25,491 households surveyed in the rural area use electricity representing about $5 \%$ of households. Also, about $80 \%$ of households in the urban area use kerosene while it is about $18 \%$ for households in the rural area. More so, the average amount (Naira) spent on clothing and footwear for urban households is about N11, 700 while it is about N7, 700 for rural households (with a gap of N4, 000 per household clothing and footwear expenditure). Average household education expenditure in the urban area is about N9, 800 while it is about N3, 800 for rural households (with a gap of N6, 000). On the other hand, urban household hospitalization is about 3,400 cases out of 9,409 households while it is about 4,300 cases out of 25,491 households for rural households. Again, about 100 households out of 9,409 households in the urban area have access to health insurance representing about $1.06 \%$ while it is worse in the rural area where only about 5 households out of 25,491 households surveyed have access to health insurance which represents about $0.02 \%$. This is particularly worrisome. Worse still, only about 433 households out of 9,409 households in the urban area can access health care facilities, this is about $4.6 \%$, while about 208 households out of 25,491 households have access to health care facilities, this represents about $0.8 \%$. From the foregoing, the study could infer that household health status is a case for concern in Nigeria while it is particularly horrible for rural dwellers. Only about 327 out of 9,409 (3.5\%) households in the urban area have access to refuse, sewage collection, disposal and other services while it is 28 out of 25,491 rural households $(0.1 \%)$ have access to refuse disposal services. Interestingly, average of 8,753 out of 9,409 (93\%) of urban households do furnishing and routine household maintenance while it is 7,343 out of 25,491 households $(29 \%)$ that do furnishing and routine household maintenance. The study also observe that about 4,087 out of 9,409 households $(43 \%)$ use petrol for private purposes while it is 1270 out of 25,491 households $(5 \%)$ in the rural areas use petrol for the same purpose. Again, only
$28 \%$ of 9,409 surveyed households in the urban area pay their property service charge, licenses and taxes while only about $0.05 \%$ of 25,491 surveyed households pay their property service charge, licenses and taxes. In terms of house rent, average actual rent paid by urban households is about $\mathrm{N} 14,000$ while actual rent paid by rural households is about $\mathrm{N} 1,700$.

Table 2. Random and fixed effects of household income on infant mortality rate

\begin{tabular}{lcc}
\hline \multirow{2}{*}{ Variables } & $(\mathbf{1})$ & $(\mathbf{2})$ \\
\cline { 2 - 3 } C & Random effect & Fixed effect \\
\hline \multirow{2}{*}{ Hhc } & $20176.49 * * *$ & $2735.65 * * *$ \\
& $(1517.083)$ & $(611.013)$ \\
Anc & .0037 & .0037 \\
& $(0.0331)$ & $(0.0469)$ \\
Sws & $-.0186^{* *}$ & -.0200 \\
& $(0.0468)$ & $(0.0469)$ \\
Med & -.0767 & -.0819 \\
& $(0.0468)$ & $(0.104)$ \\
Hhs & .00086 & 0.00078 \\
& $(0.0036)$ & $(0.0037)$ \\
& $1383.57 * * *$ & $1312.99 * *$ \\
\end{tabular}

Note: Figures in parentheses are standard errors

${ }^{* * *} \mathrm{p}<0.01,{ }^{* *} \mathrm{p}<0.05,{ }^{*} \mathrm{p}<0.1$

Table 3. OLS Result on the effects of household income on infant mortality rate

\begin{tabular}{ccc}
\hline Variables & Imr \\
\cline { 3 - 3 } & & OLS \\
\hline & C & $(1010.016)$ \\
& Hhc & .0077 \\
& Anc & $(0.0579)$ \\
& .0357 \\
& Sws & $(0.0785)$ \\
& Med & .1368 \\
& & $(0.1768)$ \\
& Hhs & .0076 \\
& $(0.0060)$ \\
& 2161.703 \\
\end{tabular}

Note: Figures in parentheses are standard errors

$* * * \mathrm{p}<0.01, * * \mathrm{p}<0.05, * \mathrm{p}<0.1$

The results from Tables 2 and 3 above show that although household income has negative effect on infant mortality, its effect on infant mortality in Nigeria is insignificant. The outcome is in tandem with [21]. The coefficients of 
household income from random and fixed effects result suggest that both estimators are unbiased having a respective value of 0.033 and 0.033 in comparison with the OLS estimator with a value of 0.058 . However, the results above suggest that household size (with p-value of 0.025) significantly affects infant mortality rates in Nigeria which suggests that increase in household size may worsen infant mortality rates given low household income in Nigeria. Other control variables like access to antenatal care, access to safe water and sanitation shows the correct signs, though insignificant while maternal education also is insignificant effect on infant mortality.

Table 4. Random and Fixed effects of household income on under-five mortality rate

\begin{tabular}{lcc}
\hline \multirow{2}{*}{ Variables } & $(\mathbf{1})$ & $(\mathbf{2})$ \\
\cline { 2 - 3 } C & Random effect & Fixed effect \\
\hline \multirow{2}{*}{ Hhc } & 494.659 & 664.4777 \\
& $(423.707)$ & $(461.972)$ \\
Anc & .00202 & .00258 \\
& $(0.0243)$ & $(0.0251)$ \\
Sws & $.16615^{* *}$ & .17510 \\
& $(0.03296)$ & $(0.0355)$ \\
Med & -.04729 & -.0437 \\
& $(0.07418)$ & $(0.07877)$ \\
Hhs & .00306 & 0.00247 \\
& $(0.0025)$ & $(0.00280)$ \\
& 77.00007 & -.87 .1727 \\
\hline
\end{tabular}

Note: Figures in parentheses are standard errors

$* * * \mathrm{p}<0.01, * * \mathrm{p}<0.05, * \mathrm{p}<0.1$

Table 5. OLS Result on the effects of household income on under-five mortality rate

\begin{tabular}{lc}
\hline \multirow{2}{*}{ Variables } & Umr \\
\cline { 2 - 3 } C & OLS \\
\hline \multirow{2}{*}{ Hhc } & 494.659 \\
& $(423.707)$ \\
Anc & .00202 \\
& $(0.02510)$ \\
Sws & .17510 \\
& $(0.03550)$ \\
Med & -.04378 \\
& $(0.07877)$ \\
Hhs & .00247 \\
& $(0.00280)$ \\
\hline
\end{tabular}

Note: Figures in parentheses are standard errors

$* * * \mathrm{p}<0.01, * * \mathrm{p}<0.05, * \mathrm{p}<0.1$

The OLS, random effect and fixed effects results in Tables 4 and 5 equally show that household income has negative but insignificant effect on under-five mortality rate. Although, access to safe water and sanitation has an inverse relationship with under-five mortality rate, access to antenatal care has significant effect on under-five mortality rate albeit negative sign. In all, the random effect and OLS estimators are good estimators since they are unbiased against each other with smaller standard errors and yield identical result while fixed effects estimator is biased upwards with a higher standard error. Also, other control variables, maternal education and household size are insignificant variables in relation to underfive mortality rate in Nigeria.

Table 6. Random and Fixed effects of household income on neonatal mortality rate

\begin{tabular}{lcc}
\hline \multirow{2}{*}{ Variables } & $(\mathbf{1})$ & $(\mathbf{2})$ \\
\cline { 2 - 3 } C & Random effect & Fixed effect \\
\hline \multirow{2}{*}{ Hhc } & $788641.5^{* * *}$ & $115193.2^{* * *}$ \\
& $(22464)$ & $(1111.327)$ \\
Anc & $.99621^{* * *}$ & $.996210^{* * *}$ \\
& $(0.06044)$ & $(0.060402)$ \\
Sws & $.15762^{*}$ & $.1567646^{*}$ \\
& $(0.08546)$ & $(0.08540)$ \\
Med & .0934069 & .0933521 \\
& $(0.18949)$ & $(0.18949)$ \\
Hhs & $.012198^{*}$ & $0.01219 *$ \\
& $(0.00674)$ & $(0.00644)$ \\
& 921.4129 & 859.0737 \\
\hline
\end{tabular}

Note: Figures in parentheses are standard errors

$* * * \mathrm{p}<0.01, * * \mathrm{p}<0.05, * \mathrm{p}<0.1$

Table 7. OLS Results on the effect of household income on neonatal mortality rate

\begin{tabular}{lc}
\hline \multirow{2}{*}{ Variables } & Nmr \\
\cline { 2 - 2 } C & OLS \\
\hline \multirow{2}{*}{ Hhc } & $-67545.22 * * *$ \\
& $(12901.15)$ \\
Anc & .7968117 \\
& $(0.74008)$ \\
Sws & $1.709334 *$ \\
& $(1.003861)$ \\
Med & -2.97075 \\
& $(2.25868)$ \\
Hhs & $.4726462 * * *$ \\
& $(0.07741)$ \\
\hline
\end{tabular}

Note: Figures in parentheses are standard errors

$* * * \mathrm{p}<0.01, * * \mathrm{p}<0.05, * \mathrm{p}<0.1$

The random effect and fixed effect results in Tables 6 and 7 is in line with theoretical expectation that household income has negative significant effect on neonatal mortality rate in Nigeria while other control variables have insignificant effect on neonatal mortality rate. However, OLS result suggests that access to safe water and sanitation has an inverse relationship with neonatal mortality rate while household size shows positive relationship with neonatal mortality rate. This implies that increase in access to safe water and sanitation engenders neonatal mortality rate while increase in household size would lead to a further increase in neonatal mortality rate in Nigeria.

\section{Conclusion}

From the findings of the study, it is evident that household income has no significant effect on infant mortality rate in Nigeria. Also health spending was found to have insignificant impact on under-five mortality rate but has significant effect 
on neonatal mortality rate in Nigeria. However, what is a little worrisome is the insignificant effect of income on infant and under-five mortality rate. This is an indication that low household income may not necessary lead to poor child development. A major policy implication that can be arrived at from the findings is that household income has not been adequately integrated into the household child-health intervention medications. It is important to note that because of urbanization, quality healthcare services are concentrated in urban areas while low household income in rural areas cannot solve their child health challenges. In this regard, balanced rural and urban health care services can be seen as a good measure for short run and long run improved health status of the citizenry. Thus, the study concludes that child mortality could significantly be reduced with increased household income in Nigeria as far as households attach great importance to child health. Also, health spending especially on programmes like access to safe drinking water

\section{Appendix}

\section{Regression Results for Model 1}

and environmental sanitation should further be increased and sustained. More importantly, government should spend well above the World Health Organization (WHO) recommended benchmark of 5 percent of gross domestic product (GDP) on health, which currently hovers around 2 percent in Nigeria. All these would go a long way in reducing the current mortality rate of 350/100, 000 as against recommended target of $250 / 1000,000$ by 2015 and beyond.

\section{Suggestion for Further Studies}

This study is by no means an exhaustive treatment of the impact of household income on child mortality in Nigeria, but will serve as a prelude for promoting further insight on this study. Further studies using other household data are therefore suggested.

\begin{tabular}{|c|c|c|c|c|c|c|}
\hline \multicolumn{4}{|c|}{$\begin{array}{l}\text { Random-effects GLS regression } \\
\text { Group variable: hImedc }\end{array}$} & \multicolumn{2}{|c|}{$\begin{array}{l}\text { Number of obs } \\
\text { Number of groups }\end{array}$} & \multirow{2}{*}{$\begin{array}{rr}= & 34900 \\
= & 2682 \\
= & 1 \\
= & 13.0 \\
= & 23907\end{array}$} \\
\hline $\begin{array}{ll}\text { R-sq: } & \text { within } \\
& \text { between } \\
\text { overa11 }\end{array}$ & $\begin{array}{l}=0.0002 \\
=0.0008 \\
=0.0002\end{array}$ & & & Obs pe & group: $\begin{array}{r}\min = \\
\text { avg }= \\
\max =\end{array}$ & \\
\hline \multicolumn{3}{|c|}{$\begin{array}{l}\text { Random effects } u_{-} i \quad \sim \text { Gaussian } \\
\operatorname{corr}\left(u_{-} i, x\right)\end{array}$} & & \multicolumn{2}{|c|}{$\begin{array}{l}\text { Wald chi2(5) } \\
\text { Prob > chi2 }\end{array}$} & $\begin{array}{r}6.34 \\
0.2748\end{array}$ \\
\hline imr & Coef. & Std. Err. & $\mathbf{z}$ & $P>|z|$ & \multicolumn{2}{|c|}{ [95\% Conf. Interval] } \\
\hline $\begin{array}{r}\text { hhic } \\
\text { anc } \\
\text { sws } \\
\text { med } \\
\text { hhs } \\
\text { ccons }\end{array}$ & $\begin{array}{r}.0037742 \\
-.0186373 \\
-.0767448 \\
.0008647 \\
1383.571 \\
20176.49\end{array}$ & $\begin{array}{r}.0331921 \\
.046806 \\
.1039378 \\
.0036911 \\
583.1928 \\
1517.083\end{array}$ & $\begin{array}{r}0.11 \\
-0.40 \\
-0.74 \\
0.23 \\
2.37 \\
13.30\end{array}$ & $\begin{array}{l}0.909 \\
0.690 \\
0.460 \\
0.815 \\
0.018 \\
0.000\end{array}$ & $\begin{array}{r}-.0612812 \\
-.1103754 \\
-.2804592 \\
-.0063697 \\
240.5339 \\
17203.06\end{array}$ & $\begin{array}{l}.0688296 \\
.0731009 \\
.1269696 \\
.0080991 \\
2526.608 \\
23149.92\end{array}$ \\
\hline $\begin{array}{r}\text { sigma_u } \\
\text { sigma_e } \\
\text { rho }\end{array}$ & $\begin{array}{l}69507.506 \\
19378.892 \\
.92787529\end{array}$ & \multicolumn{5}{|c|}{ (fraction of variance due to $u_{-} i$ ) } \\
\hline \multicolumn{7}{|c|}{. xtreg imr hhic anc sws med hhs, fe } \\
\hline \multicolumn{4}{|c|}{$\begin{array}{l}\text { Fixed-effects (within) regression } \\
\text { Group variable: hlmedc }\end{array}$} & \multicolumn{2}{|c|}{$\begin{array}{l}\text { Number of obs } \\
\text { Number of groups }\end{array}$} & $\begin{array}{r}34900 \\
2682\end{array}$ \\
\hline $\begin{array}{ll}\text { R-sq: } & \text { within } \\
\text { between } \\
\text { overa11 }\end{array}$ & $\begin{array}{l}=0.0002 \\
=0.0007 \\
=0.0002\end{array}$ & & & Obs pe & group: $\begin{array}{r}\min = \\
\operatorname{avg}= \\
\max =\end{array}$ & $\begin{array}{r}1 \\
13.0 \\
23907\end{array}$ \\
\hline $\operatorname{corr}\left(u_{-} i, x b\right)$ & $=0.0061$ & & & $\begin{array}{l}\mathrm{F}(5,32 \\
\mathrm{Prob}>\end{array}$ & & $\begin{array}{r}1.16 \\
0.3251\end{array}$ \\
\hline$i m r$ & Coef. & Std. Err. & $\mathbf{t}$ & $P>|t|$ & [95\% Conf & Interval] \\
\hline $\begin{array}{r}\text { hhic } \\
\text { anc } \\
\text { sws } \\
\text { med } \\
\text { hhs } \\
\text { _cons }\end{array}$ & $\begin{array}{r}.0037319 \\
-.0200259 \\
-.0819543 \\
.000789 \\
1312.99 \\
2735.656\end{array}$ & $\begin{array}{l}.0332097 \\
.0469568 \\
.1041849 \\
.0037083 \\
585.2934 \\
611.0113\end{array}$ & $\begin{array}{r}0.11 \\
-0.43 \\
-0.79 \\
0.21 \\
2.24 \\
4.48\end{array}$ & $\begin{array}{l}0.911 \\
0.670 \\
0.432 \\
0.832 \\
0.025 \\
0.000\end{array}$ & $\begin{array}{r}-.0613604 \\
-.112063 \\
-.2861606 \\
-.0064795 \\
165.7931 \\
1538.051\end{array}$ & $\begin{array}{r}.0688242 \\
.0720112 \\
.122252 \\
.0080575 \\
2460.187 \\
3933.261\end{array}$ \\
\hline $\begin{array}{r}\text { sigma_u } \\
\text { sigma_e } \\
\text { rho }\end{array}$ & $\begin{array}{l}71638.562 \\
19378.892 \\
.93181427\end{array}$ & (fraction & var & ce due & $\left.u \_i\right)$ & \\
\hline
\end{tabular}

F test that a11 $u_{-} i=0: \quad F(2681,32213)=27.92 \quad$ Prob $>F=0.0000$ 
- reg imr hhic anc sws med hhs

\begin{tabular}{r|crc} 
Source & SS & df & MS \\
\hline Mode1 & $8.9811 \mathrm{e}+09$ & 5 & $1.7962 \mathrm{e}+09$ \\
Residua1 & $4.0206 \mathrm{e}+13$ & 34894 & $1.1522 \mathrm{e}+09$ \\
\hline Tota1 & $4.0215 \mathrm{e}+13$ & 34899 & $1.1523 \mathrm{e}+09$
\end{tabular}

$\begin{array}{lrr}\text { Number of obs } & = & 34900 \\ \mathrm{~F}(5,34894) & = & 1.56 \\ \text { Prob }>\mathrm{F} & = & 0.1680 \\ \text { R-squared } & = & 0.0002 \\ \text { Adj R-squared } & = & 0.0001 \\ \text { Root MSE } & = & 33944\end{array}$

\begin{tabular}{r|rrrrrr}
\hline imr & Coef. & Std. Err. & $t$ & $\mathrm{P}>|\mathrm{t}|$ & [95\% Conf. Interva1] \\
\hline hhic & .0027589 & .0579403 & 0.05 & 0.962 & -.1108059 & .1163236 \\
anc & .0357495 & .0785911 & 0.45 & 0.649 & -.1182916 & .1897905 \\
sws & -.1368823 & .1768296 & -0.77 & 0.439 & -.483474 & .2097094 \\
med & .0076679 & .0060611 & 1.27 & 0.206 & -.004212 & .0195478 \\
hhs & 2161.703 & 965.7681 & 2.24 & 0.025 & 268.7669 & 4054.64 \\
_cons & 1813.619 & 1010.016 & 1.80 & 0.073 & -166.0436 & 3793.282 \\
\hline
\end{tabular}

Regression Result for Model 2

\begin{tabular}{|c|c|c|c|c|c|c|c|}
\hline \multicolumn{4}{|c|}{$\begin{array}{l}\text { Random-effects GLS regression } \\
\text { Group variable: hlmedc }\end{array}$} & \multicolumn{2}{|c|}{$\begin{array}{l}\text { Number of obs } \\
\text { Number of groups }\end{array}$} & \multicolumn{2}{|c|}{$\begin{array}{l}=\quad 34900 \\
=\quad 2682\end{array}$} \\
\hline $\begin{array}{ll}\text { R-sq: } & \text { within } \\
& \text { betwee } \\
\text { overal }\end{array}$ & $\begin{array}{l}=0.0008 \\
=0.0012 \\
=0.0008\end{array}$ & & & obs pe & group: $\begin{array}{r}\text { mi } \\
\text { av } \\
\text { ma }\end{array}$ & $\begin{array}{l}= \\
=\end{array}$ & $\begin{array}{r}1 \\
13.0 \\
23907\end{array}$ \\
\hline \multicolumn{4}{|c|}{$\begin{array}{l}\left.\text { Random effects } u_{-} i\right) \text { Gaussian } \\
\operatorname{corr}\left(u_{-} i, x\right) \\
=0 \text { (assumed) }\end{array}$} & \multicolumn{2}{|c|}{$\begin{array}{l}\text { Wald chi2(5) } \\
\text { Prob > chi2 }\end{array}$} & $\begin{array}{l}= \\
=\end{array}$ & $\begin{array}{r}27.62 \\
0.0000\end{array}$ \\
\hline umr & Coef. & Std. Err. & $\mathbf{z}$ & $P>|z|$ & {$[95 \%$ co } & f. & Interva1] \\
\hline $\begin{array}{r}\text { hhic } \\
\text { anc } \\
\text { sws } \\
\text { med } \\
\text { hhs } \\
\text { _cons }\end{array}$ & $\begin{array}{r}.0020226 \\
.1661504 \\
-.0472984 \\
.0030699 \\
77.00007 \\
494.659\end{array}$ & $\begin{array}{r}.0243062 \\
.0329694 \\
.074181 \\
.0025427 \\
405.145 \\
423.707\end{array}$ & $\begin{array}{r}0.08 \\
5.04 \\
-0.64 \\
1.21 \\
0.19 \\
1.17\end{array}$ & $\begin{array}{l}0.934 \\
0.000 \\
0.524 \\
0.227 \\
0.849 \\
0.243\end{array}$ & $\begin{array}{r}-.045616 \\
.101531 \\
-.192690 \\
-.001913 \\
-717.069 \\
-335.791\end{array}$ & & $\begin{array}{r}.049662 \\
.2307692 \\
.0980937 \\
.0080535 \\
871.0696 \\
1325.11\end{array}$ \\
\hline $\begin{array}{r}\text { sigma_u } \\
\text { sigma_e } \\
\text { rho }\end{array}$ & $\begin{array}{r}0 \\
14651.958 \\
0\end{array}$ & (fraction & var & ce due & $\left.u_{-} i\right)$ & & \\
\hline
\end{tabular}

- xtreg umr hhic anc sws med hhs, fe

\begin{tabular}{|c|c|c|c|c|c|c|c|}
\hline $\begin{array}{l}\text { Fixed-effects } \\
\text { Group variable }\end{array}$ & $\begin{array}{l}\text { (within) reg } \\
\text { : hlmedc }\end{array}$ & ssion & & $\begin{array}{l}\text { Number } \\
\text { Number }\end{array}$ & $\begin{array}{l}\text { obs } \\
\text { groups }\end{array}$ & $=$ & $\begin{array}{r}34900 \\
2682\end{array}$ \\
\hline $\begin{array}{ll}\text { R-sq: } & \text { within } \\
& \text { between } \\
\text { overa11 }\end{array}$ & $\begin{array}{l}=0.0008 \\
=0.0007 \\
=0.0008\end{array}$ & & & obs pe & oup: mi & $\begin{array}{l}= \\
=\end{array}$ & $\begin{array}{r}1 \\
13.0 \\
23907\end{array}$ \\
\hline $\operatorname{corr}\left(u_{-} i, x b\right)$ & $=-0.0076$ & & & $\begin{array}{l}F(5,32 \\
\text { Prob > }\end{array}$ & & $\begin{array}{l}= \\
=\end{array}$ & $\begin{array}{r}5.11 \\
0.0001\end{array}$ \\
\hline umr & Coef. & Std. Err. & $t$ & $P>|t|$ & {$[95 \%$ co } & f. & Interval] \\
\hline $\begin{array}{r}\text { hhic } \\
\text { anc } \\
\text { sws } \\
\text { med } \\
\text { hhs } \\
\text { _cons }\end{array}$ & $\begin{array}{r}.0025863 \\
.1751023 \\
-.0437854 \\
.0024749 \\
-87.1727 \\
664.4777\end{array}$ & $\begin{array}{r}.0251091 \\
.035503 \\
.0787719 \\
.0028038 \\
442.5275 \\
461.9723\end{array}$ & $\begin{array}{r}0.10 \\
4.93 \\
-0.56 \\
0.88 \\
-0.20 \\
1.44\end{array}$ & $\begin{array}{l}0.918 \\
0.000 \\
0.578 \\
0.377 \\
0.844 \\
0.150\end{array}$ & $\begin{array}{r}-.046628 \\
.105515 \\
-.198181 \\
-.003020 \\
-954.543 \\
-241.005\end{array}$ & & $\begin{array}{r}.0518012 \\
.2446896 \\
.1106105 \\
.0079705 \\
780.1979 \\
1569.961\end{array}$ \\
\hline $\begin{array}{r}\text { sigma_u } \\
\text { sigma_e } \\
\text { rho }\end{array}$ & $\begin{array}{l}4928.2377 \\
14651.958 \\
.10163532\end{array}$ & (fraction & val & du & $\left.u_{-} \mathbf{i}\right)$ & & \\
\hline
\end{tabular}


- reg umr hhic anc sws med hhs

\begin{tabular}{r|crr} 
Source & SS & df & MS \\
\hline $\begin{array}{r}\text { Mode1 } \\
\text { Residual }\end{array}$ & $\begin{array}{l}5.5998 \mathrm{e}+09 \\
7.0756 \mathrm{e}+12\end{array}$ & 34894 & $1.1200 \mathrm{e}+09$ \\
\hline Total & $7.0812 \mathrm{e}+12$ & 34899 & 202773057 \\
\hline
\end{tabular}

Number of obs $=34900$

$F(5,34894)=5.52$

Prob > F $=0.0000$

R-squared $=0.0008$

Adj R-squared $=0.0006$

ROOt MSE $=14240$

\begin{tabular}{r|rrrrrr}
\hline umr & Coef. & Std. Err. & $\mathrm{t}$ & $\mathrm{P}>|\mathrm{t}|$ & [95\% Conf. Interva1] \\
\hline hhic & .0020226 & .0243062 & 0.08 & 0.934 & -.0456184 & .0496637 \\
anc & .1661504 & .0329694 & 5.04 & 0.000 & .1015293 & .2307714 \\
sws & -.0472984 & .074181 & -0.64 & 0.524 & -.1926955 & .0980987 \\
med & .0030699 & .0025427 & 1.21 & 0.227 & -.0019138 & .0080536 \\
hhs & 77.00007 & 405.145 & 0.19 & 0.849 & -717.097 & 871.0972 \\
cons & 494.659 & 423.707 & 1.17 & 0.243 & -335.8204 & 1325.138
\end{tabular}

Regression Result for Model 3

\begin{tabular}{|c|c|c|c|c|c|c|}
\hline \multicolumn{4}{|c|}{$\begin{array}{l}\text { Random-effects GLS regression } \\
\text { Group variable: } h 1 \text { medc }\end{array}$} & \multicolumn{2}{|c|}{$\begin{array}{l}\text { Number of obs } \\
\text { Number of groups }\end{array}$} & $\begin{array}{r}34900 \\
2682\end{array}$ \\
\hline \multicolumn{4}{|c|}{$\begin{aligned} \text { R-sq: } & \text { within }=0.0087 \\
\text { between } & =0.0023 \\
\text { overal1 } & =0.0003\end{aligned}$} & \multicolumn{3}{|c|}{ obs per group: $\begin{aligned} & \min = \\
& \operatorname{avg}= \\
& \max =\end{aligned}$} \\
\hline \multicolumn{4}{|c|}{$\begin{array}{l}\text { Random effects } u_{-} i \quad \sim \text { Gaussian } \\
\operatorname{corr}\left(u_{-} i, x\right)\end{array}$} & \multicolumn{2}{|c|}{$\begin{array}{l}\text { Wald chi2(5) } \\
\text { Prob > chi2 }\end{array}$} & $\begin{array}{l}280.91 \\
0.0000\end{array}$ \\
\hline $\mathrm{nmr}$ & Coef. & Std. Err. & z & $P>|z|$ & [95\% Conf & F. Interva1] \\
\hline $\begin{array}{r}\text { hhic } \\
\text { anc } \\
\text { Sws } \\
\text { med } \\
\text { hhs } \\
\text { _cons }\end{array}$ & $\begin{array}{l}.996123 \\
.1576276 \\
.0934069 \\
.0123247 \\
921.4129 \\
788641.5\end{array}$ & $\begin{array}{r}.0604432 \\
.0854606 \\
.1896167 \\
.006749 \\
1065.219 \\
22464.38\end{array}$ & $\begin{array}{r}16.48 \\
1.84 \\
0.49 \\
1.83 \\
0.86 \\
35.11\end{array}$ & $\begin{array}{l}0.000 \\
0.065 \\
0.622 \\
0.068 \\
0.387 \\
0.000\end{array}$ & $\begin{array}{r}.8776565 \\
-.0098721 \\
-.2782351 \\
-.0009031 \\
-1166.377 \\
744612.1\end{array}$ & $\begin{array}{r}1.11459 \\
.3251272 \\
.4650488 \\
.0255525 \\
3009.203 \\
832670.9\end{array}$ \\
\hline $\begin{array}{r}\text { sigma_u } \\
\text { sigma_e } \\
\text { rho }\end{array}$ & $\begin{array}{l}1160676.7 \\
35246.935 \\
.99907866\end{array}$ & (fraction & f varia & ce due & $\left.u_{-} i\right)$ & \\
\hline
\end{tabular}

- xtreg nmr hhic anc sws med hhs, fe

\begin{tabular}{|c|c|c|c|c|}
\hline $\begin{array}{l}\text { Fixed- } \\
\text { Group }\end{array}$ & $\begin{array}{l}\text { effects (within) regression } \\
\text { variable: hlmedc }\end{array}$ & $\begin{array}{l}\text { Number of obs } \\
\text { Number of groups }\end{array}$ & & $\begin{array}{r}34900 \\
2682\end{array}$ \\
\hline R-sq: & $\begin{array}{l}\text { within }=0.0087 \\
\text { between }=0.0021 \\
\text { overa11 }=0.0002\end{array}$ & obs per group: & & $\begin{array}{r}1 \\
13.0 \\
23907\end{array}$ \\
\hline $\operatorname{corr}(u$ & $-i, x b)=0.0085$ & $\begin{array}{l}\mathrm{F}(5,32213) \\
\text { Prob }>\mathrm{F}\end{array}$ & & $\begin{array}{r}56.22 \\
0.0000\end{array}$ \\
\hline
\end{tabular}

\begin{tabular}{r|rrrrrr}
\hline nmr & Coef. & Std. Err. & $\mathrm{t}$ & $\mathrm{P}>|\mathrm{t}|$ & \multicolumn{2}{r}{ [95\% Conf. Interva1] } \\
\hline hhic & .9962107 & .0604029 & 16.49 & 0.000 & .8778188 & 1.114603 \\
anc & .1567646 & .0854065 & 1.84 & 0.066 & -.0106353 & .3241645 \\
SWs & .0933521 & .1894947 & 0.49 & 0.622 & -.2780647 & .4647689 \\
med & .0121981 & .0067449 & 1.81 & 0.071 & -.0010221 & .0254183 \\
hhs & 859.0737 & 1064.55 & 0.81 & 0.420 & -1227.484 & 2945.632 \\
_cons & 115193.2 & 1111.327 & 103.65 & 0.000 & 113014.9 & 117371.4 \\
\hline sigma_u & 1171233.5 & & & & \\
sigma_e & 35246.935 & (fraction of variance due to u_i) \\
rho & .99909518 & (fralion &
\end{tabular}

F test that al1 $u_{-} i=0: \quad F(2681,32213)=1957.44 \quad$ Prob $>F=0.0000$ 
. reg nmr hhic anc sws med hhs

\begin{tabular}{r|crc} 
Source & SS & df & MS \\
\hline Mode1 & $4.9313 \mathrm{e}+13$ & 5 & $9.8625 \mathrm{e}+12$ \\
Residua1 & $6.5597 \mathrm{e}+15$ & 34894 & $1.8799 \mathrm{e}+11$ \\
\hline Total & $6.6091 \mathrm{e}+15$ & 34899 & $1.8938 \mathrm{e}+11$
\end{tabular}

$\begin{array}{lll}\text { Number of obs } & = & 34900 \\ \mathrm{~F}(5,34894) & = & 52.46 \\ \text { Prob }>\mathrm{F} & = & 0.0000 \\ \text { R-squared } & = & 0.0075 \\ \text { Adj R-squared } & = & 0.0073 \\ \text { Root MSE } & = & 4.3 e+05\end{array}$

\begin{tabular}{r|rrrrrr}
\hline nmr & Coef. & Std. Err. & $t$ & P $>|t|$ & [95\% Conf. Interva1] \\
\hline hhic & .7968117 & .7400836 & 1.08 & 0.282 & -.6537757 & 2.247399 \\
anc & 1.709334 & 1.003861 & 1.70 & 0.089 & -.2582658 & 3.676934 \\
sws & -2.970754 & 2.258683 & -1.32 & 0.188 & -7.397846 & 1.456338 \\
med & .4726462 & .0774196 & 6.10 & 0.000 & .3209013 & .6243912 \\
hhs & 175469.7 & 12335.97 & 14.22 & 0.000 & 151290.8 & 199648.6 \\
_cons & -67545.22 & 12901.15 & -5.24 & 0.000 & -92831.89 & -42258.55 \\
\hline
\end{tabular}

\section{- xttest0}

Breusch and Pagan Lagrangian multiplier test for random effects

$n m r[h 1$ medc, $t]=x b+u[h]$ medc $]+e[h 1$ medc,$t]$

Estimated results:

\begin{tabular}{r|cc} 
& var & sd $=$ sqrt(Var) \\
\hline $\mathrm{nmr}$ & $1.89 \mathrm{e}+11$ & 435174.2 \\
$\mathrm{e}$ & $1.24 \mathrm{e}+09$ & 35246.94 \\
$\mathrm{u}$ & $1.35 \mathrm{e}+12$ & 1160677
\end{tabular}

Test: $\quad \operatorname{var}(u)=0$ $\begin{array}{rr}\operatorname{chi} 2(1)= & 1.2 \mathrm{e}+06 \\ \text { Prob }>\text { chi2 }= & 0.0000\end{array}$
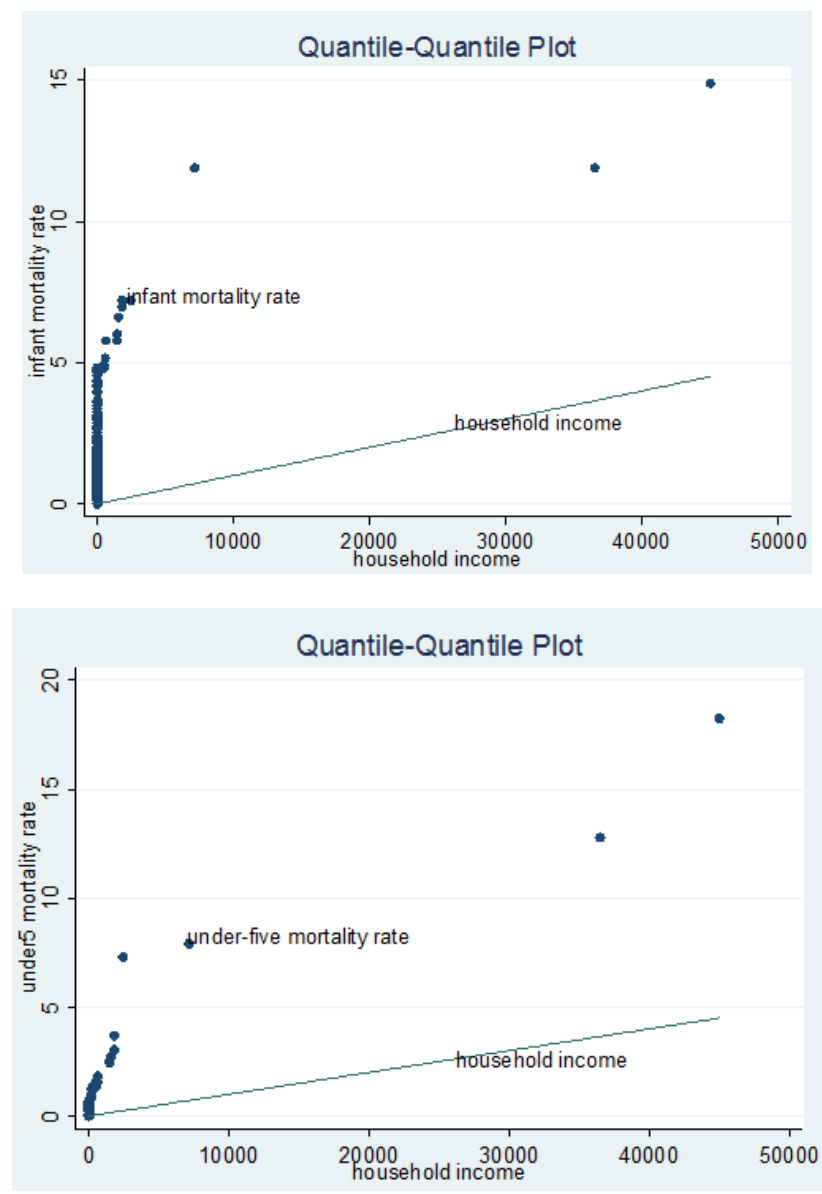

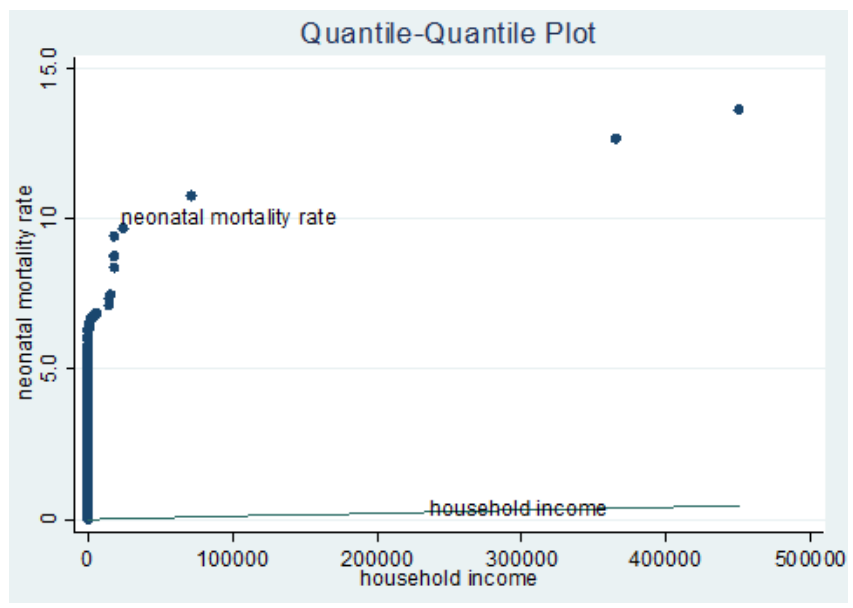

JEL Classification: D1; D6

\section{References}

[1] S. L Adeyemi, U.A. Raheed and F.B. Olorunfemi, "UnderFive Mortality and the Environment of Health in the Third World: A Nigerian Example," Journal of Human Ecology, vol. 24, no. 2, 2009.

[2] B.A Ahonsi, "Developmental Implications of Early Mortality Factors in Nigeria," Journal of Social Development in Africa, vol. 7, no. 1, 1992.

[3] D. Antai, "Migration and Child Immunization in Nigeria: Individual and Community Level Contexts," BMC Public Health, vol. 10, no. 1, 2010. 
[4] E.G Backland, P.D Sorlie and N.J Johnson, "The Shape of the Relationship between Income and Mortality in United States: Evidence from the National Longitudinal Mortality Study," Annual Epidemiol, vol. 6, no. 2, 2007.

[5] J. C Caldwell, "Routes to Low Mortality in Poor Countries," Population and Development Review, vol. 12, no. 2, 2006.

[6] S.H Cochrane, "The Socioeconomic Determinants of Mortality: The Cross-national Evidence", In: The Effects of Education on Health, World Bank Working Paper 405, 2000.

[7] M.S Cousins, L. M Shickle and J.A Bander, "An Introduction to Predictive Modeling for Disease Management Risk Stratification," Disease Management, vol. 5, no. 3, 2002.

[8] M. Daly, G. Duncan, G.A Kaplan and J.W Lynch, "Macro-toMicro Linkages in the Inequality-Mortality Relationship". Milbank Memorial Fund 76, 1998.

[9] A. V Diez-Roux, "Investigating Neighborhood and Area Effect on Health," American Journal of Public Health, vol. 91 , no. 3,2001

[10] R. Ecob and S.G Davey, "Income and Health: What is the Nature of the Relationship?" Social Science Medicine, vol. 48, no. 3,1999 .

[11] K. Fiscella and P. Franks, "Poverty or Income Inequality as Predictor of Mortality: Longitudinal Cohort Study," BMJ, vol. 314 , no. $6,2007$.

[12] Federal Ministry of Health/WHO Nigeria, National study on Essential Obstetric Care Facilities in Nigeria. Abuja: Federal Ministry of Health, Nigeria, 2006.

[13] Federal Ministry of Health, National Integrated Maternal, Newborn, and Child Health Strategy. Abuja: Federal Ministry of Health, Nigeria, 2010.

[14] B. Folasade, "Environmental Factors, Situation of Women and Child Mortality in South Western Nigeria," Social Science and Medicine, vol. 51, no. 1, 2000, http://dx.doi.org/10.1016/S0277-9536 (00)00047-2.

[15] H. Gravelle, "How Much of the Relation between Population Mortality and Unequal Distribution of Income is A Statistical Artefact?" BMJ, vol. 16, no. 3, 1998.

[16] H.L Guyatt, R.W. Snow and D.B Evans, "Malaria Epidemiology and Economics: The Effect of Delayed Immune Acquisition on the Cost-effectiveness of Insecticide-treated Bednets," The Royal Society, vol. 354, no. 4, 1999.

[17] A. Hala, "The Effect of Water and Sanitation on Child Mortality in Egypt. Environmental Economics Unit, 2002, Department of Economics, Gothenburg University, 2002.

[18] J.N Hobcraft, N.G MacDonald and W.S Rustein, "Socioeconomic Factors in Infant and Child Mortality: A Cross-national Comparism," Population Statistics, vol. 38, no. 2, 1984 .

[19] H. Jacoby and L. Wang, "Environmental Determinants of Child Mortality in Rural China: A Competing Risks Approach”. Washington DC: World Bank, 2003.

[20] M.K Jinadu, S.O Olusi, J.I Agun and A.K Fabiyi, "Childhood Diarrhea in Rural Nigeria: Studies on Prevalence, Mortality and Socio-Environmental Factors," Journal of Diarrhoea Diseases Research, vol. 9, no. 4, 2011.

[21] I. Kawachi and B Kennedy, "The Health of Nations: Why
Inequality Is Harmful to Your Health". New York, NY: New Press, 2012.

[22] B. Klaauw and L Wang, "Child Mortality in Rural India". World Bank Working Paper, Washington DC: World Bank, 2003.

[23] J. S Koopman and J.W Lynch, "Individual Causal Models and Population Systems Models in Epidemiology," American Journal of Public Health, vol. 89, no. 2, 2007.

[24] J. W Lynch, G.A Kaplan and E.R Pamuk, "Income Inequality and Mortality In Metropolitan Areas of the United States," American Journal of Public Health, vol. 88, no. 7, 2005.

[25] J. W Lynch and G.A Kaplan, "Understanding How Inequality in the Distribution of Income Affects Health," Journal of Health Psychology, vol. 2, no. 2, 1997.

[26] M. Marmot, D.S George, S. Stephan, S., Chandra, P., Fiona, N., Jenny, H., Ian, W., Eric B., and F. Amanda, "Health Inequalities Among British Civil Servants: The Whitehall II Study", Lancet, vol. 337, 1991.

[27] R. Merton and A. Kitt, "Contributions to the Theory of Reference Group Behavior in Studies in the Scope and Method of "The American Soldier" The Free Press, 1950.

[28] G.C Mesike, Adeleke, I. A. and A. Ibiwoye, "Predictive Actuarial Modeling of Health Insurance Claims Costs," International Journal of Mathematics and Computation, vol. 14, no. 1, 2011.

[29] MICS, "Multiple Indicator Cluster Survey, Nigeria”, 2008.

[30] J. N Mojekwu and L.A Ajijola, "Developing a Model for Estimating Infant Mortality rate of Nigeria," Journal of Research in International Business and Management, vol. 1 no. 2,2011 .

[31] W. Mosley and L.C Chen, "An Analytical Framework for the Study of Child Survival in Developing Countries," Population and Development Review, vol. 10, no. 2, 1984.

[32] C.J Mutunga, "Environmental Determinants of Child Mortality in Kenya". UNU-WIDER Research paper No. 2007/83. Helsinki: United Nations University World Institute for Development Economics Research, Academic Research, vol. 2 , no. $2,2007$.

[33] NDHS, "Nigerian Demographic and Health Survey Report", Abuja, 2003.

[34] NDHS, "Nigerian Demographic and Health Survey Report", Abuja, 2008.

[35] P. O Ogunjuyigbe, "Under-Five Mortality in Nigeria: Perception and Attitude of the Yoruba towards the Existence of Abiku," Demographic Research, vol. 11, no. 2, 2004.

[36] R.K Ojikutu, "Malaria and Child Survival in Nigeria: Beyond the Stethoscope," International Journal of Academic Research, vol. 2 , no. $2,2010$.

[37] S.B Omer, D.A Salmon, W.A Orenstein, P. De-Hart and N. Halsey, "Vaccine Refusal, Mandatory Immunization, and the Risks of Vaccine-Preventable Diseases," Journal of Medicine, vol. 360 , no. $1,2009$.

[38] B.C Ozumba and E.E Nwogu-Ikojo, "Avoidable Maternal in Enugu, Nigeria," Public Health, vol. 122, no. 4, pp. 354-360, 2008, http://dx.doi.org/10.1016/j.puhe.2007.04.018. 
[39] K. M Rahman, M and P. Sarkar, 'Determinants of Infant and Child Mortality in Bangladesh," Pakistan Journal of Social Sciences, vol. 6, no. 3, 2009.

[40] G. Ridder and I. Tunali, "Stratified Partial Likelihood Estimation". Journal of Econometrics, vol. 92, pp. 193-232, 1999, http://dx.doi.org/10.1016/S0304-4076 (98)00090-6.

[41] S.O Rutstein, "Guide to DHS Statistics". Calverton, MD: Demographic and Health Surveys, ORC Macro, 2001.

[42] T. Schultz, "Studying the Impact of Household Economic and Community Variables on Child Mortality". Population and Development Review, vol. 10, no. 2, 1984, http://dx.doi.org/10.2307/2807962.

[43] G. Singh and M. Kogan, "Persistent Socioeconomic Disparities in Infant, Neonatal, And Post-Neonatal Mortality Rates in the United States, 1969-2001," Pediatrics, vol. 119, no. $4,2007.4$ Available at: www.pediatrics.org/cgi/content/full/119/4/e928.

[44] G. Singh and S. Yu, "Infant mortality in the United States: Trends, Differentials, Projection, 1950 -2010". American Journal of Public Health., vol. 85, no. 7, 2005.

[45] C.E Stein, Birmingham, M., Kurian, M., Duclos, P and P. Strebel, "The Global Burden of Measles in the Year 2000-A Model That Uses Country-Specific Indicators" Journal of Infectious Diseases, vol. 187, no. 1, 2012.

[46] UNICEF, "The State of the World's Children". New York: United Nations Children's Fund, 2010.

[47] UNICEF, "Assessment of the Impact of Rising Food and Commodity Prices on Childhood Malnutrition in Nigeria", Commissioned Study, Abuja, January 2009.
[48] A. Wagstaff and E. Doorslaer, "Income Inequality and Health: What Does the Literature Tell Us?," Annual Review of Public Health, vol. 21, no. 3, 2010.

[49] N.J Waitzman and K.R Smith, "Separate but Lethal: The Effects of Economic Segregation on Mortality in Metropolitan America," Milbank Memorial Fund, vol. 76, no. 3, 1998.

[50] L. Wang, "Environmental Determinants of Child Mortality: Empirical Results from the 2000 Ethiopia DHS". Washington DC: World Bank, 2003.

[51] WHO, World Health Organization Report, "Making a Difference", Geneva, 2010.

[52] R. Wilkinson, The Impact of Inequality, New York, NY: New Press, 2005.

[53] M. Wolfson, Kaplan, G.A., Lynch, J.W., Ross, N and E. Backlund, "The Relation between Income Inequality and Mortality is not a Statistical Artefact”. BMJ, vol. 319: 953957, 1998.

[54] WHO, "Making Pregnancy Safer: The Critical Role of the Skilled Attendant". A Joint Statement by WHO, ICM and FIGO WHO, Geneva, 2005.

[55] D. You, G. Jones, G and T. Wardlaw, United Nations Interagency Group for Child Mortality Estimation, Levels and Trends In Child Mortality: Estimated Developed by the UN Inter-agency Group for Child Mortality Estimation. New York: UNICEF, 2010.

[56] Y. Zhao, S.A Ash, H. John and M. Benjamin, "Identifying Future High-Cost Cases through Predictive Modeling". Disease Management and Health Outcomes, vol. 11, no. 6, 2003. 